\title{
Faktor-Faktor yang Berhubungan dengan Kualitas Hidup Pasien Thalassemia Mayor di Pusat Thalassemia Departemen IImu Kesehatan Anak RSCM
}

\author{
Daniel Nugraha Aji, Christopher Silman, Citra Aryudi, Cynthia, Centauri, Damara Andalia, Desi \\ Astari, Diah Pitaloka DMP, Corry Wawolumaya, ${ }^{* *}$ Rini Sekartini, * Pustika Amalia* \\ Mahasiswa FKUI, *Departemen Ilmu Kesehatan Anak FKUI-RSCM, **Departemen Ilmu Kedokteran \\ Komunitas FKUI
}

\begin{abstract}
Latar belakang. Transfusi darah dan terapi kelasi yang diberikan seumur hidup pada anak dengan thalassemia mayor memberikan harapan hidup yang sama dengan anak sehat. Kualitas hidup menjadi hal yang penting dengan bertambahnya angka harapan hidup pasien thalassemia.

Tujuan. Mengetahui kualitas hidup anak dengan thalassemia mayor di Pusat Thalassemia Departemen Ilmu Kesehatan Anak FKUI-RSCM serta faktor-faktor yang berhubungan.

Metode. Penelitian menggunakan rancangan cross-sectional. Pengambilan sampel dilakukan secara konsekutif pada bulan Juli 2009. Subjek penelitian adalah anak berusia 13-18 tahun di Pusat Thalassemia Departemen Ilmu Kesehatan Anak FKUI-RSCM yang datang selama periode penelitian. Penilaian kualitas hidup menggunakan kuesioner baku PedsQL yang diisi sendiri oleh subjek. Analisis data dengan metode univariat dengan tingkat kemaknaan $\alpha=0,05$.

Hasil. Dari 97 subjek, 49 (50,5\%) memiliki kualitas hidup buruk. Sebaran usia, jenis kelamin, dan pendapatan orang tua berturut-turut didapatkan pada 53 subjek (54,6\%) berusia 13-15 tahun, 49 subjek (50,5\%) perempuan, dan 53 subjek $(54,6 \%)$ memiliki orang tua berpendapatan menengah. Kelompok suku bangsa terbanyak adalah Sunda-Sunda (32\%). Perubahan fisis dialami oleh $78 \%$ subjek yang terdiri dari facies Cooley (58\%), hiperpigmentasi (64\%), dan perut membuncit (26\%). Faktor yang berhubungan dengan kualitas hidup adalah tingkat pendapatan orang tua $(p=0,037)$, suku bangsa $(p=0,019)$, dan tampilan facies cooley $(p=0,006)$.

Kesimpulan. Separuh anak dengan thalassemia mayor di Pusat Thalassemia RSCM (50,5\%) memiliki kualitas hidup yang buruk. Kualitas hidup tersebut berhubungan dengan tingkat pendapatan orang tua, suku, dan tampilan facies Cooley. (Sari Pediatri 2009;11(2):85-9).
\end{abstract}

Kata kunci: thalassemia mayor, anak, kualitas hidup, PedsQL

\footnotetext{
Alamat korespondensi

Dr. Pustika Amalia, Sp.A(K). Divisi Hematologi-Onkologi Departemen Ilmu Kesehatan Anak FKUI- RSCM Jl. Salemba no. 6, Jakarta 10430. Telepon: 021-3907744, 31901170, Fax.:021-3913982.
}

halassemia merupakan kelompok kelainan
genetik yang ditandai berkurangnya sintesis
salah satu dari dua tipe rantai polipeptida
$(-\alpha$ atau $-\beta)$ yang membentuk molekul normal hemoglobin manusia dewasa $\left(\mathrm{HbA}, \alpha_{2} \beta_{2}\right) .{ }^{1} \mathrm{Hal}$ 
tersebut akan menyebabkan isi hemoglobin dalam sel darah merah berkurang dan manifestasi klinis berupa anemia. Berdasarkan gen yang terlibat, thalassemia dapat dibedakan menjadi thalassemia- $\alpha$ dan thalassemia- $\beta$. Gambaran klinis pasien thalassemia bervariasi, mulai dari tanpa gejala hingga yang bergantung pada transfusi darah. pasien yang bergantung pada transfusi darah ini disebut thalassemia mayor. ${ }^{1}$

Thalassemia merupakan salah satu masalah kesehatan di dunia dan Indonesia. World Health Organization (WHO) pada tahun 1994 menyatakan bahwa sekitar $4,5 \%$ dari total penduduk dunia adalah pembawa sifat kelainan ini. Dari jumlah tersebut sebanyak 80-90 juta adalah pembawa sifat thalassemia- $\beta$ dan sisanya adalah pembawa sifat thalassemia- $\alpha$ dan hemoglobinopati ( $\mathrm{HbE}, \mathrm{HbS}, \mathrm{HbO}$, dan lain lain). ${ }^{2}$ Di Indonesia, thalassemia merupakan kelainan genetik yang paling banyak ditemukan. Di Pusat Thalassemia Departemen Ilmu Kesehatan Anak (IKA) Fakultas Kedokteran Universitas Indonesia (FKUI) Rumah Sakit Cipto Mangunkusumo (RSCM) sampai dengan akhir tahun 2008 terdaftar 1.455 pasien yang terdiri dari $50 \%$ thalassemia- $\beta, 48,2 \%$ thalassemia- $\beta / \mathrm{Hb}-\mathrm{E}$, dan $1,8 \%$ pasien thalassemia- $\alpha .{ }^{2}$ Diperkirakan tiap tahunnya di Indonesia lahir 2.500 anak dengan thalassemia. Jumlah pasien yang tinggi tersebut merupakan beban tersendiri baik bagi keluarga pasien maupun pemerintah. Biaya pengobatan suportif berupa transfusi darah dan kelasi besi mencapai Rp 200-300 juta/tahun/pasien. ${ }^{2}$

Sebuah penelitian di India menunjukkan sebagian besar pasien thalassemia (74\%) ternyata memilliki kualitas hidup yang buruk. ${ }^{3}$ Tidak hanya itu, sekitar 44\% memiliki masalah psikologis seperti gejala cemas, depresi, dan gangguan perilaku. ${ }^{3}$ Penelitian yang dilakukan di Malaysia juga menampilkan hasil yang serupa. Kualitas hidup anak dengan thalassemia lebih rendah dibandingkan kelompok kontrol anak sehat. Thalassemia memiliki efek negatif terhadap fungsi fisis, emosi, sosial, dan kemampuan bersekolah. ${ }^{4}$

Kualitas hidup yang rendah pada pasien thalassemia mayor berkaitan dengan berbagai macam faktor, misalnya diagnosis dan tata laksana, perjalanan penyakit yang kronis, penampilan, frekuensi kunjungan ke rumah sakit untuk transfusi darah, keterlambatan perkembangan seksual, infertilitas, komplikasi penyakit, gangguan psikiatri dan lain-lain. ${ }^{5}$ Penelitian kami bertujuan untuk mengetahui kualitas hidup dan fakor-faktor yang berhubungan dengan pasien thalassemia mayor.

\section{Metode}

Penelitian dilakukan di Pusat Thalassemia Departemen IKA FKUI RSCM pada bulan Juli 2009 menggunakan rancangan cross-sectional. Subjek penelitian adalah anak dengan thalassemia mayor berusia 13-18 tahun yang terdaftar di Pusat Thalassemia Departemen IKA FKUI RSCM, datang pada waktu penelitian, dan memenuhi kriteria inklusi serta eksklusi. Pengambilan data dilakukan secara konsekutif. Sumber data terdiri atas data primer dan data sekunder. Data primer diperoleh dengan anamnesis dan menggunakan kuesioner PedsQL yang sudah diterjemahkan ke dalam bahasa Indonesia dan diisi sendiri oleh pasien. Data sekunder lainnya diperoleh dari rekam medis pasien.

Pada subjek dilakukan anamnesis dan pemeriksaan fisik meliputi faktor-faktor yang berhubungan dengan kualitas hidup anak dengan thalassemia, yaitu usia, jenis kelamin, tingkat pendidikan subjek, pendidikan ayah dan ibu, pendapatan orang tua, suku, jenis thalassemia mayor, usia saat diagnosis, lama sakit, rerata kadar hemoglobin pra-transfusi,dan frekuensi transfusi. Sedangkan pemeriksaan fisik meliputi perubahan fisik, penampilan facies Cooley, perubahan warna kulit, tampilan perut yang membuncit, riwayat splenektomi, terapi kelasi, dan infeksi terkait transfusi darah.

Pengukuran kualitas hidup anak dengan thalassemia mayor menggunakan instrumen kuesioner Pediatric Quality of Life Inventory (PedsQL) 4.0 untuk kelompok usia 13-18 tahun tersedia dalam bahasa Inggris yang diterjemahkan ke bahasa Indonesia. Kuesioner PedsQL terdiri dari 23 pertanyaan untuk mengukur empat skala multidimensi yaitu fungsi fisis (8 pertanyaan), fungsi emosional (5 pertanyaan), fungsi sosial (5 pertanyaan), dan fungsi sekolah ( 5 pertanyaan). Dari 23 pertanyaan tersebut didapatkan tiga hasil akhir yaitu hasil total (total summary score), hasil keseluruhan kesehatan fisis (physical health summary), dan hasil keseluruhan kesehatan psikis (psychological health summary).

Setiap skala mendapat penilaian secara terbalik, untuk setiap pemilihan angka nol (tidak pernah) mendapat nilai 100, satu (sangat jarang) mendapat 75, dua (kadang-kadang) mendapat 50, tiga (sering) mendapat 25, dan empat (selalu) mendapat nilai nol. Semakin tinggi nilainya, semakin baik kualitas hidup responden. Nilai total didata sebagai nilai mean berdasarkan jumlah pertanyaan terjawab pada penilaian fisis dan psikologis. Nilai fisis menggambarkan aspek 
kesehatan, sedangkan nilai psikologis menggambarkan respon dari kondisi emosional, sosial, dan fungsi sekolah. Berdasarkan literatur, maka ditetapkan bila total summary score $<70$ maka kualitas hidup pasien buruk. ${ }^{6}$ Fungsi psikososial, fungsi fisis, fungsi emosional, fungsi sekolah, dan fungsi sosial ditetapkan sebagai buruk bila $<80$. $^{7}$

Data yang diperoleh disajikan dalam bentuk narasi dan tabel. Uji statistik yang digunakan adalah chi square dengan alternatif uji Fisher bila tidak memenuhi syarat uji chi square. Program yang digunakan adalah SPSS 13.0 dengan tingkat kemaknaan $\alpha=0,05$.

\section{Hasil}

Subjek yang diteliti berjumlah 97 orang. Sebaran subjek meliputi karakteristik demografis dan karakteristik

Tabel 1. Karakteristik demografis subjek penelitian $(n=97)$

\begin{tabular}{|c|c|c|}
\hline Karakteristik & $\mathrm{n}$ & $\%$ \\
\hline \multicolumn{3}{|l|}{$\overline{\text { Usia(tahun) }}$} \\
\hline $13-15$ & 53 & 54,6 \\
\hline $16-18$ & 44 & 45,4 \\
\hline \multicolumn{3}{|l|}{ Jenis kelamin } \\
\hline Lelaki & 48 & 49,5 \\
\hline Perempuan & 49 & 50,5 \\
\hline \multicolumn{3}{|l|}{ Tingkat pendidikan } \\
\hline Putus sekolah & 17 & 17,5 \\
\hline SD & 4 & 4,1 \\
\hline SMP & 42 & 43,3 \\
\hline SMA & 33 & 34,0 \\
\hline Perguruan tinggi & 1 & 1,0 \\
\hline \multicolumn{3}{|l|}{ Pendidikan ayah } \\
\hline Rendah & 42 & 43,3 \\
\hline Sedang & 47 & 48,5 \\
\hline Tinggi & 8 & 8,2 \\
\hline \multicolumn{3}{|l|}{ Pendidikan ibu } \\
\hline Rendah & 55 & 56,7 \\
\hline Sedang & 34 & 35,1 \\
\hline Tinggi & 8 & 8,2 \\
\hline \multicolumn{3}{|l|}{ Pendapatan orangtua } \\
\hline Rendah & 32 & 33,0 \\
\hline Menengah & 53 & 54,6 \\
\hline Menengah atas & 12 & 12,4 \\
\hline Tinggi & 0 & 0 \\
\hline \multicolumn{3}{|l|}{ Suku } \\
\hline Sunda-Sunda & 31 & 32,0 \\
\hline Jawa-Jawa & 14 & 14,4 \\
\hline Jawa-Sunda & 10 & 10,3 \\
\hline Jawa-Betawi & 10 & 10,3 \\
\hline Betawi-Sunda & 10 & 10,3 \\
\hline Betawi-Betawi & 9 & 9,3 \\
\hline Tionghoa-Tionghoa & 2 & 2,1 \\
\hline Lain-lain & 11 & 11,3 \\
\hline
\end{tabular}

klinis tertera pada Tabel 1 dan 2. Usia subjek yang terbanyak 13 tahun $(24,7 \%)$ dengan median 15 tahun. Dari total 97 subjek, 54,6\% berada pada rentang usia 13-15 tahun dan 45,4\% berada pada rentang usia 1618. Proporsi jenis kelamin subjek penelitian seimbang antara laki-laki dan perempuan.

Berdasarkan penilaian kualitas hidup dengan kuesioner PedsQL yang diterjemahkan ke bahasa Indonesia, setengah dari subjek (50,5\%) memiliki kualitas hidup buruk. Fungsi yang paling terganggu adalah fungsi sekolah, (89,7\%) subjek memiliki fungsi sekolah yang buruk (Tabel 3). Sementara itu proporsi subjek dengan kualitas hidup baik paling besar terdapat pada fungsi sosial. Berdasarkan analisis

Tabel 2. Karakteristik klinis subjek penelitian $(\mathrm{n}=97)$

\begin{tabular}{|c|c|c|}
\hline Karakteristik & $\mathrm{n}$ & $\%$ \\
\hline \multicolumn{3}{|l|}{ Jenis thalassemia mayor } \\
\hline Thalassemia- $\beta$ & 49 & 50,5 \\
\hline Thalassemia- $\beta / \mathrm{HbE}$ & 48 & 49,5 \\
\hline Thalassemia- $\alpha$ & 0 & 0 \\
\hline \multicolumn{3}{|c|}{ Usia saat diagnosis (tahun) } \\
\hline $0-1$ & 48 & 49,5 \\
\hline$>1-5$ & 29 & 29,9 \\
\hline$>5$ & 20 & 20,6 \\
\hline \multicolumn{3}{|l|}{ Lama sakit (tahun) } \\
\hline$<1$ & 1 & 1 \\
\hline $1-5$ & 9 & 9,3 \\
\hline$>5$ & 87 & 89,7 \\
\hline \multicolumn{3}{|c|}{ Rerata Hb pra-transfusi (g/dL) } \\
\hline$<6$ & 14 & 14,4 \\
\hline $6-8$ & 75 & 77,3 \\
\hline$>8-10$ & 8 & 8,3 \\
\hline \multicolumn{3}{|c|}{ Frekuensi transfusi (tahun) } \\
\hline$<12$ kali & 33 & 34,0 \\
\hline$\geq 12$ kali & 64 & 66,0 \\
\hline \multicolumn{3}{|l|}{ Perubahan fisis } \\
\hline $\mathrm{Ya}$ & 78 & 80,4 \\
\hline Facies Cooley & 58 & 59,8 \\
\hline Hiperpigmentasi & 64 & 66 \\
\hline Perut buncit & 26 & 26,8 \\
\hline Fraktur patologis & 1 & 1 \\
\hline Tidak & 19 & 19,6 \\
\hline \multicolumn{3}{|l|}{ Riwayat splenektomi } \\
\hline $\mathrm{Ya}$ & 16 & 16,5 \\
\hline Tidak & 81 & 83,5 \\
\hline \multicolumn{3}{|l|}{ Terapi kelasi } \\
\hline Teratur & 72 & 74,2 \\
\hline Tidak teratur & 24 & 24,7 \\
\hline Tidak pernah & 1 & 1 \\
\hline \multicolumn{3}{|l|}{ Infeksi terkait transfusi } \\
\hline Ya & 23 & 23,7 \\
\hline Hepatitis B & 13 & 13,4 \\
\hline Hepatitis C & 13 & 13,4 \\
\hline HIV & 0 & 0 \\
\hline Tidak & 74 & 76,3 \\
\hline
\end{tabular}


Daniel Nugraha Aji dkk: Faktor-faktor yang berhubungan dengan kualitas hidup pasien thalassemia mayor

Tabel 3. Sebaran subjek berdasarkan kualitas hidup

\begin{tabular}{|c|c|c|c|c|}
\hline \multirow{3}{*}{ Domain } & \multicolumn{4}{|c|}{ Kualitas hidup } \\
\hline & \multicolumn{2}{|c|}{ Baik } & \multicolumn{2}{|c|}{ Buruk } \\
\hline & $\mathrm{n}$ & $\%$ & $\mathrm{n}$ & $\%$ \\
\hline Fungsi fisis & 30 & 30,9 & 67 & 69,1 \\
\hline Fungsi emosional & 32 & 33 & 65 & 67 \\
\hline Fungsi sosial & 57 & 58,8 & 40 & 41,2 \\
\hline Fungsi sekolah & 10 & 10,3 & 87 & 89,7 \\
\hline Fungsi psikososial & 22 & 22,7 & 75 & 77,3 \\
\hline Fungsi secara total & 48 & 49,5 & 49 & 50,5 \\
\hline
\end{tabular}

statistik, kuesioner PedsQL yang diterjemahkan ke bahasa Indonesia yang digunakan dalam penelitian valid dan memiliki reliabilitas yang baik dengan Alfa Cronbach 0,835.

Variabel bebas dan variabel terikat pada penelitian kami merupakan variabel kategorik. Dari variabel yang diteliti, faktor yang berhubungan dengan kualitas hidup adalah tingkat pendapatan orang tua $(p=0,037)$, suku $(p=0,019)$, dan tampilan facies cooley $(p=0,006)$.

Analisis hubungan juga dilakukan antara variabel bebas dengan kualitas hidup yang dapat dibagi dalam kelompok fungsi fisis, emosional, sosial, sekolah, dan psikososial. Terdapat hubungan bermakna antara kelompok suku bangsa dengan kualitas hidup berdasarkan fungsi fisis $(p=0,005)$. Ditemukan pula hubungan bermakna antara adanya infeksi dengan kualitas hidup berdasarkan fungsi fisis $(p=0,045)$ dan perubahan fisis dan kualitas hidup berdasarkan fungsi psikososial $(p=0,034)$. Juga terdapat hubungan bermakna antara tingkat pendidikan subjek dan kualitas hidup berdasarkan fungsi sosial $(p=0,030)$, suku dan kualitas hidup berdasarkan fungsi sosial $(p=0,046)$, rerata $\mathrm{Hb}$ pra-transfusi dan kualitas hidup berdasarkan fungsi sosial $(p=0,013)$. Terdapat pula hubungan antara adanya perubahan fisis dengan kualitas hidup berdasarkan fungsi sekolah $(p=0,023)$.

\section{Diskusi}

Kuesioner PedsQL yang sudah diterjemahkan ke Bahasa Indonesia dan memiliki reliabilitas yang baik dengan Alfa Cronbach 0,835 telah digunakan dalam penelitian kami. Kuesioner ini dapat menilai kualitas hidup subjek berdasarkan fungsi secara total yang dapat dibagi menjadi fungsi fisis, emosional, sosial, sekolah, dan psikososial. Fungsi sekolah adalah fungsi yang paling terganggu $(89,7 \%)$. Temuan tersebut sesuai dengan penelitian Mahityutthana ${ }^{8}$ di Thailand pada tahun 2007 dan Ismail $\mathrm{A}^{4}$ di Malaysia pada tahun 2006 yang menyatakan bahwa pasien thalassemia memiliki kualitas hidup yang buruk terutama dalam fungsi sekolah.

Buruknya fungsi sekolah diduga akibat tingginya frekuensi anak dengan thalassemia yang harus meninggalkan sekolah untuk mendapat pengobatan di rumah sakit. Pada penelitian kami faktor yang berhubungan dengan fungsi sekolah adalah adanya perubahan fisis $(p=0,023)$. Hal tersebut dapat dikaitkan

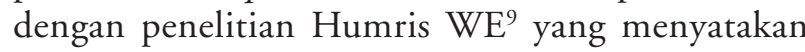
bahwa penampilan pasien thalassemia menyebabkan citra yang kurang baik, timbulnya rasa malu, penolakan untuk bergaul, dan bersekolah.

Fungsi psikososial adalah fungsi kedua yang terganggu setelah fungsi sekolah. Didapatkan hubungan yang bermakna antara perubahan fisis dengan fungsi psikososial $(p=0,034)$. Hal itu sesuai kepustakaan, perubahan fisis subjek menyebabkan gangguan kepercayaan diri dalam pergaulan sehari-hari. Selain itu, keterbatasan aktivitas fisis juga membuat subjek tidak dapat melakukan hal-hal yang dapat dilakukan oleh teman-teman sebaya yang sehat.

Hampir tujuh puluh persen subjek yang memiliki fungsi fisis buruk. Aspek fisis memainkan peran utama, terutama karena perubahan penampilan fisis dari pasien thalassemia yang sangat mencolok. Perubahan fisis ini menurut Modell dan Berdoukas disebabkan karena anemia kronis dan pengendapan zat besi pada organ-organ tubuh. Perubahan fisis yang terjadi berupa deformitas tulang wajah, splenomegali, ekspansi sumsum tulang, tubuh pendek, dan berbagai gejala yang diakibatkan oleh proses hemolisis. ${ }^{9}$

Sehingga penampilan pasien thalassemia pada fase lanjut berbeda dengan anak sehat. Perbedaan fisis tersebut sangat mencolok ketika pasien mencapai usia remaja. Penampilan yang berbeda merupakan faktor penting yang mempengaruhi perkembangan kepribadian seperti citra diri yang kurang, timbul rasa 
malu, penolakan untuk bergaul, dan bersekolah. ${ }^{?}$

Gangguan fungsi emosional dipengaruhi oleh berbagai hal, yaitu perasaan tertekan saat penegakkan diagnosis penyakit, terapi yang harus dijalani setiap bulan secara teratur, dan keharusan tidak masuk sekolah karena harus menjalani terapi. Masalah emosi pada pasien dewasa terjadi berkaitan dengan pencarian pekerjaan, mencari pasangan hidup, membangun keluarga. Di lain pihak terapi thalassemia yang baik menyebabkan anak-anak thalassemia dapat tumbuh sesuai dengan anak normal. Misalnya, transfusi darah untuk menjaga kadar hemoglobin pasien menyebabkan pasien dapat menjalani pekerjaan rutin sama seperti anak sehat lainnya. Informasi tentang thalassemia yang lebih luas menyebabkan pasien thalassemia mulai dapat diterima oleh masyarakat. Dijumpai bahwa fungsi sosial berhubungan dengan tingkat pendidikan subjek $(p=0,030)$, suku $(p=0,046)$, dan rerata hemoglobin pra-transfusi $(0,013)$.

Semakin rendah pendidikan subjek maka fungsi sosial subjek semakin buruk. Kelompok suku Jawa/ Sunda cenderung memiliki fungsi sosial yang lebih baik, dan semakin tinggi rerata hemoglobin pratransfusi subjek maka fungsi sosial semakin baik.

Ditemukan hubungan antara pendapatan orang tua dengan kualitas hidup anaknya yang menderita thalassemia $(p=0,037)$, semakin tinggi tingkat pendapatan orang tua maka kualitas hidup anak cenderung semakin baik. Hal ini didukung oleh data yang didapatkan data dari Pusat Thalassemia Departemen Ilmu Kesehatan Anak FKUI RSCM didapatkan bahwa biaya pengobatan anak thalassemia selama satu tahun sebesar tiga ratus juta rupiah. ${ }^{2}$ Maka jelas pendapatan orangtua diharapkan dapat mendukung tata laksana pasien (misalnya transportasi ke rumah sakit, biaya kelasi besi, dan transplantasi sumsum tulang) sehingga dapat meningkatkan kualitas hidup.

\section{Kesimpulan}

Lima puluh persen anak usia 13-18 tahun dengan thalassemia mayor yang berobat di Pusat Thalassemia Departemen IKA FKUI RSCM memiliki kualitas hidup buruk. Dalam proses tumbuh kemabng anak, $89,7 \%$ dan $77,3 \%$ subjek berturut-turut memiliki fungsi sekolah dan fungsi psikososial yang buruk. Terdapat hubungan antara tingkat pendapatan orang tua, suku, dan tampilan facies Cooley dengan kualitas hidup anak dengan thalassemia mayor.

\section{Daftar Pustaka}

1. Capellini N, Cohen A, Eleftheriou A, Piga A, Porter J. Guidelines for the clinical management of thalassaemia. Thalassaemia International Federation; 2000.

2. Wahidiyat PAW. Faktor-faktor genetik pengubah manifestasi klinis thalassemia- $\beta / \mathrm{HbE}$ : interaksi antara mutasi thalassemia- $\beta,-\alpha$, polimorfisme Xmnl-G $\gamma$, dan SNPs pada klaster gen globin- $\beta$. Disertasi. Jakarta: Fakultas Kedokteran Universitas Indonesia; 2009.

3. Shaligram D, Girimaji SC, Chaturvedi SK. Psychological problems and quality of life in children with thalassemia. Indian J Pediatr 2007;74:727-30.

4. Ismail A, Campbell MJ, Ibrahim HM, Jones GL. Health related quality of life in Malaysian Children thalassaemia. Health and Quality of Life Outcomes 2006;4:39.

5. Jafari H, Lahsaeizadeh S, Jafari P, Karimi M. Quality of life in thalassemia major: reliability and validity of the Persian version of SF-36 questionnaire. J Postgrad Med 2008;54:273-5.

6. Varni JW, Burwinkle TM, Seid M. The PedsQL patient report outcome: reliability and validity of the PedsQLtm Measurement Model in 25.000 children. Rand Health 2005.h.705-10.

7. Brown L. The healthy families program health status assessment (PedsQLTM ). Final Report. 2004.

8. Mahityutthana J. Health-related quality of life and satisfaction with health service of thalassemia patients. Tesis. Thailand: Mahidol University; 2007.

9. Humris WE. Penyakit thalassemia mayor sebagai faktor pencetus psikopatologi pada anak dan orang tuanya. Disertasi. Jakarta: Fakultas Kedokteran Universitas Indonesia; 2001. 